\title{
Effect of Superfine Grinding on Antidiabetic Activity of Bitter Melon Powder
}

\author{
Ying Zhu, Ying Dong *, Xiwen Qian, Fengjie Cui, Qin Guo, Xinghua Zhou, Yun Wang, \\ Yi Zhang and Zhiyu Xiong
}

School of Food and Biological Engineering, Jiangsu University, Zhenjiang 212013, China; E-Mails: ying307@126.com (Y.Z.); xwqian@126.com (X.Q.); fengjiecui@163.com (F.C.); guoqin_shiyin@163.com (Q.G.); xinghuazhou638@163.com (X.Z.); wangy1974@ujs.edu.cn (Y.W.); zhangyihahahei@126.com (Y.Z.); xzy19880304@163.com (Z.X.)

* Author to whom correspondence should be addressed; E-Mail: ydong@ujs.edu.cn; Tel.: +86-511-8879-7202; Fax: +86-511-8878-0201.

Received: 22 August 2012; in revised form: 19 October 2012 / Accepted: 23 October 2012 / Published: 2 November 2012

\begin{abstract}
The antidiabetic activities of bitter melon powders produced with lyophilization/superfine grinding and hot air drying/normal grinding were investigated in vivo for selecting a suitable bitter melon processing procedure. After a five-week treatment, bitter melon lyophilized superfine grinding powder (BLSP) had a higher antidiabetic activity with reducing fasting blood glucose levels from 21.40 to $12.54 \mathrm{mmol} / \mathrm{L}$, the serum insulin levels from 40.93 to $30.74 \mathrm{mIU} / \mathrm{L}$, and restoring activities of SOD compared with those in the bitter melon hot air drying powder (BAP) treated group. Furthermore, BLSP protected pancreatic tissues including islet beta cells and reduced the loss of islet cells. Combined with the difference of compositions in BLSP and BAP, it could be concluded that superfine grinding and lyophilization processes were beneficial for presenting the antidiabetic activity, which will provide a reference for direct utilization of bitter melon as a suitable functional food to relieve symptoms of diabetes.
\end{abstract}

Keywords: bitter melon powder; diabetes; superfine grinding; anti-diabetic activity; food processing 


\section{Introduction}

Momordica charantia Linn. (Cucurbitaceae) is referred to as bitter melon or bitter gourd and has recently attracted considerable attention for its various physiological activities, such as its antitumor [1-3], anti-inflammatory [4], antioxidant [5,6], antibacterial [7,8], hypoglycemic [9-11], hypocholesterolemic [12], hypotriglyceridemic [13], and immunostimulating activities [14]. Previous investigations have shown that the fruits and leaves of $M$. charantia had rich phenolics and exhibited a high antioxidant activity [5]. Nowadays, it has been used as a traditional antidiabetic remedy in eastern countries and areas for many years [11,15]. Fresh bitter melon is also used as a nourishing food, as it contains: $93.8 \%$ water, $0.9 \%$ protein, $0.1 \%$ lipid, $3.3 \%$ dietary fiber, $20 \mathrm{~kJ}$ energy per $100 \mathrm{~g}, 0.6 \%$ ash, and a small quantity, $0.05 \%$, of vitamin C [16].

The antidiabetic evaluation of bitter melon has been well investigated in streptozocin- or alloxan-induced diabetic rats, mice and rabbits, high-fat diet-induced obesity mice, as well as in humans with type 2 diabetes [9,13,17-20]. The hypoglycemic potential components in bitter melon have been identified as glycosides, saponins, alkaloids, triterpenes, polysaccharides, proteins, and steroids [14,21]. Although several pure chemicals were isolated from bitter melon and applied for investigating their antidiabetic mechanisms, the mixture of these hypoglycemic chemicals such as saponins or charantins seemed to present a significantly higher bioactivity. For example, the hypoglycemic chemicals of bitter melon are proven as a mixture of steroidal saponins known as charantins and alkaloids [21]. The antidiabetic mechanisms of bitter melon also have been proposed. Bitter melon has shown to stimulate glycogen storage by liver and insulin secretion by islets of Langerhans [13,22]. Bitter melon suppresses weight gain and has the potential to reduce adiposity [23]. Moreover, bitter melon supplementation lowered serum and hepatic triglyceride in normal rats [24]. Bitter melon may possess insulin-like properties, preserved pancreatic islet beta cells [23,25]. A recent study proved that bitter melon could upregulate the significance of glucose transporter 4 (GLUT-4), peroxisome proliferator-activated receptor $\gamma$ (PPAR $\gamma$ ) and phosphatidylinositol 3 kinase (PI3K) by augmenting the glucose uptake and homeostasis [26]. Bitter melon can also improve insulin sensitivity by increasing insulin-stimulated insulin receptor substrate-1 (IRS1) tyrosine phosphorylation in high-fat diet-fed mice/rats [27,28]. Hence, the synergic effect of these bioactive components would possibly make the contribution. Therefore, the question is: "Do we need to evaluate the antidiabetic activity of bitter melon by using purified samples?"

Superfine grinding technology is a new technology and a useful tool for preparing superfine powder [29]. Compared with other samples ground with traditional mechanical methods, superfine powder bears good physical properties like dispersibility and solubility. To date, the superfine grinding technology has also been applied in biotechnology and foodstuffs and shown a high potential for many other commercial applications [30]. For example, the Astragalus membranaceus powder obtained with superfine grinding had high water-holding capacity, high fluidity, high water solubility index and high protein solubility [31]. Now, Chinese markets sell the bitter melon powder processed by hot drying and milling which might result in the inactivation of components in the samples. Nevertheless, lyophilized bitter melon had also previously been superfine-ground with its particle size less than $50 \mu \mathrm{m}$ by our group. Similar to other foodstuffs, superfine grinding bitter melon powder after the lyophilization process retains the whole chemical compositions of fresh samples, such as proteins, polysaccharides, 
glycosides, saponins, alkaloids, and triterpenes, while its physical properties received significant changes after the grinding process. However, few references are presented for evaluating the antidiabetic activity of superfine grinding bitter melon powder containing a total of bioactive compositions.

The objectives of this study were: (1) to obtain the bitter melon lyophilized superfine grinding powder (BLSP) and bitter melon hot air drying superfine grinding powder (BAP); (2) to compare their differences in physical/chemical properties, antidiabetic activity and their mechanisms in vivo; and, (3) to conclude the processing effect on the bioactivity of bitter melon.

\section{Results and Discussion}

\subsection{Physical and Chemical Properties of Superfine-Ground Bitter Melon}

Figure 1 presented the morphology of fragmented bitter melon powder. BLSP had the better uniformity with a particle size of 3-10 $\mu \mathrm{m}$, while the particle size of BAP was $50-150 \mu \mathrm{m}$. After superfine grinding, the water content of the powder reduced from $5.92 \%$ to $2.66 \%$, and the water solubility index increased from $37.82 \%$ to $39.38 \%$ (Table 1 ).

Figure 1. SEM images of BAP and BLSP.

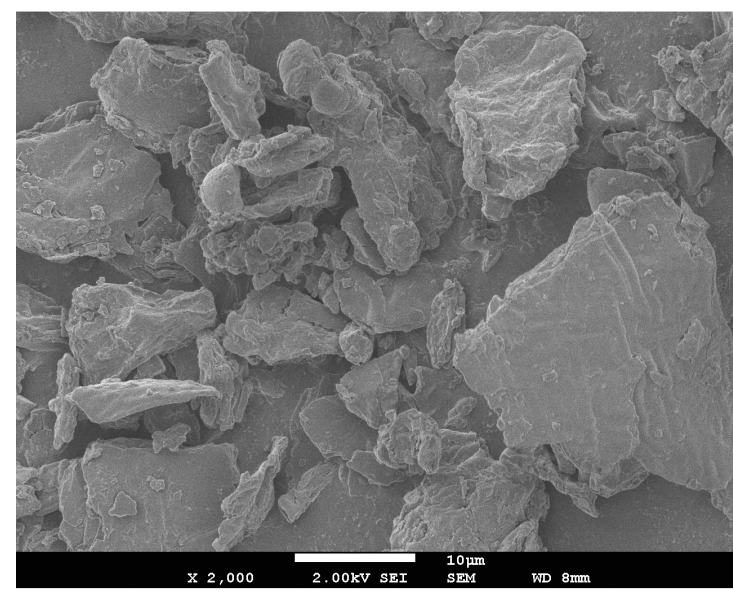

BAP

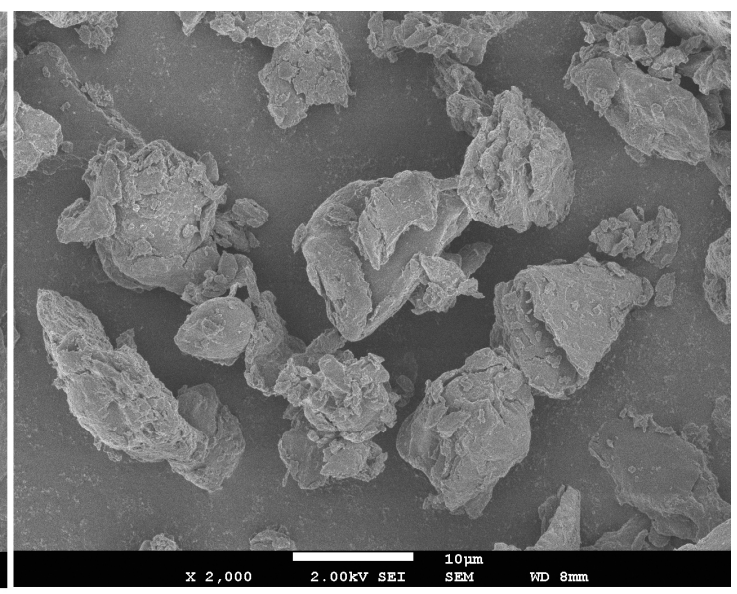

BLSP

Table 1. Physical analysis of BLSP and BAP.

\begin{tabular}{ccccc}
\hline Sample & Mean diameter $(\boldsymbol{\mu m})$ & Moisture $(\%)$ & Aw & Water solubility index $(\%)$ \\
\hline BLSP & 6.5 & $2.66 \pm 0.05^{\mathrm{b}}$ & $0.37 \pm 0.01^{\mathrm{a}}$ & $39.38 \pm 0.04^{\mathrm{a}}$ \\
BAP & 100 & $5.92 \pm 0.06^{\mathrm{a}}$ & $0.34 \pm 0.01^{\mathrm{a}}$ & $37.82 \pm 0.03^{\mathrm{b}}$ \\
\hline
\end{tabular}

Values are expressed as means $\pm \mathrm{SD}(n=3)$. Statistical analysis was performed using ANOVA. The means with different superscript were considered significantly different $(p<0.05)$.

The chemical composition of BLSP and BAP are shown in Table 2. BLSP had higher total polyphenols of $10.03 \mathrm{mg} / \mathrm{g}$ and total flavonoids of $5.27 \mathrm{mg} / \mathrm{g}$ compared with BAP $(p<0.05)$. Meanwhile, the decrease in particle size of bitter melon resulted in the increase of the water-soluble sugar levels and the water-soluble protein contents $(p<0.05)$. The total saponins content of BLSP was 
$2.74 \%$, significant higher than BAP $(p<0.05)$. These results imply that superfine grinding is helpful for improving the extraction efficiency of the nutritional components of bitter melon.

Table 2. Contents of main chemical components of BLSP and BAP.

\begin{tabular}{cccccc}
\hline Sample & $\begin{array}{c}\text { Water-soluble } \\
\text { protein }(\mathbf{m g} / \mathbf{g})\end{array}$ & $\begin{array}{c}\text { Water-soluble } \\
\text { sugar }(\mathbf{\%})\end{array}$ & $\begin{array}{c}\text { Total polyphenols } \\
(\mathbf{m g} / \mathbf{g})\end{array}$ & $\begin{array}{c}\text { Total flavonoids } \\
(\mathbf{m g} / \mathbf{g})\end{array}$ & $\begin{array}{c}\text { Total } \\
\text { saponins }(\mathbf{\%})\end{array}$ \\
\hline BLSP & $2.99 \pm 0.04^{\mathrm{a}}$ & $13.07 \pm 0.11^{\mathrm{a}}$ & $10.03 \pm 0.02^{\mathrm{a}}$ & $5.27 \pm 0.05^{\mathrm{a}}$ & $2.74 \pm 0.01^{\mathrm{a}}$ \\
BAP & $2.17 \pm 0.06^{\mathrm{b}}$ & $11.01 \pm 0.09^{\mathrm{b}}$ & $6.43 \pm 0.04^{\mathrm{b}}$ & $2.09 \pm 0.04^{\mathrm{b}}$ & $2.00 \pm 0.02^{\mathrm{b}}$ \\
\hline \multicolumn{5}{c}{ Values are expressed as means $\pm \mathrm{SD}(n=3)$. Statistical analysis was performed using ANOVA. The means } \\
\multicolumn{5}{r}{ with different superscript were considered significantly different $(p<0.05)}$.
\end{tabular}

Temperature can promote oxidation of polyphenols and flavanoids, BAP was processed by $60{ }^{\circ} \mathrm{C}$ hot air drying while BLSP was lyophilized (the high temperature was $5{ }^{\circ} \mathrm{C}$ ). Hence, the contents of polyphenols and flavanoids in BAP are lower than BLSP. The powder with particle size less than 10-25 $\mu \mathrm{m}$ was defined as superfine material and possessed a narrow and uniform particle size distribution with good surface area that ensure easy dispersibility, solubility and flowability [29,32]. Nowadays, the superfine grinding technology has been widely used in the food processing industry. The superfine grinding could cause marked differences in chemical composition separation of the granulometric fractions [33], and the hydration rate and the bioavailability of materials increased [34]. This helps to promote the digestion and absorption of samples. For example, superfine grinding affects the composition and hydration properties of the wheat bran dietary fiber (DF) products with the decrease of particle size [35]. Superfine green tea had a better water content of $4.52 \%$, held the stable green and bright color, and increased the concentrations of other components including catechins, tea polysaccharide [36]. In this study, the contents of total polyphenols, total flavonoids, total saponins, water-soluble protein and sugar in BLSP were higher than those in BAP. The results suggest that superfine grinding is helpful for releasing the nutritional components from bitter melon. However, we have not given the detailed chemical analysis of these major ingredients in this paper, such as polyphenols, flavonoids and saponins; in future experiments, we will focus on these by HPLC/HPLC-MS.

Superfine grinding also improves the bioactivities of experimental materials. For example, the superfine wheat bran DF had increased antioxidant activities including chelating activity, reducing power and total phenolic content (TPC) [35]. A similar conclusion was also obtained that superfine grinding markedly increased extraction of tea polysaccharide (TPS) and that of the potent scavenging capacity of green tea powder (GTP) [36]. The present study presented the antidiabetic differences between bitter melon powders after lyophilization/superfine grinding and hot air drying/normal grinding processes for the first time.

\subsection{Effect of Processing Methods of Bitter Melon on Body Weight, Food and Water Intakes in Control and Diabetic Rats}

The changes in body weight are shown in Figure 2. At the beginning of the experiment, body weights of the diabetic groups were lower than those of two control groups, but with no statistical differences $(p>0.05)$. After a five-week treatment, bitter melon did not affect the body weight of diabetic groups significantly while body weights of the two normal groups increased significantly from 
$430 \mathrm{~g}$ to $480 \mathrm{~g}(p<0.05)$ and the nontreated diabetic group only increased the body weight by $0.82 \mathrm{~g}$ (Table 3). BLSP and BAP treatment had no effect on daily water intake. The diabetic rats treated with $800 \mathrm{mg} / \mathrm{kg} /$ day BLSP significantly reduced their food intake and improved on food efficiency ratio (food efficiency ratio $=$ body weight gain/food intake $\times 100 \%$ ) as compared with the DC group rats $(p<0.05)$ [37-39]. Several studies have reported that feeding rats a high-fat diet leads to the development of insulin resistance [40,41]. STZ can selectively target and destroy the pancreatic islet beta cells and also can make cells less active [42]. The effects of STZ on glucose and insulin homeostasis reflect the toxin-induced abnormalities in beta cell function. Srinivasan et al. developed the diabetic rat model by the combination of high-fat diet-fed and low-dose STZ-treated; this model replicated the natural history and metabolism of human Type 2 diabetes [43]. The experimental diabetic rat model used in this study was induced by a high-fat diet and low-dose STZ of $35 \mathrm{mg} / \mathrm{kg}$ bw, which closely mimic the metabolic characteristics of the type 2 diabetes in humans [37-39]. Results from this study show that the diabetic rats' body weights were significantly decreased $(p<0.5)$ compared with those of NC group. The weight loss might be associated with the abnormalities in carbohydrate, fat, and protein metabolism, which was confirmed from the water intake and food intake data.

Kasbia et al. found that a single dose of freeze-dried bitter melon $50 \mathrm{mg} / \mathrm{kg}$ and $100 \mathrm{mg} / \mathrm{kg}$ given to healthy volunteers did not reduce fasting glucose or plasma glucose after OGTT [44]. Therefore, the dosage of $400 \mathrm{mg} / \mathrm{kg}$ bw was selected in the present study due to its equivalence to an adult (60 $\mathrm{kg}$ ) taking 24 g BLSP (about $384 \mathrm{~g}$ fresh bitter melon) per day, which is acceptable for the adult daily intake for the antidiabetic effect, but with no adverse effects.

Figure 2. Effect of BLSP and BAP on mean weekly body weight in diabetic rats. Values are expressed as means $\pm \mathrm{SD}(n=6)$. Statistical analysis was performed using ANOVA. The means with different superscript were considered significantly different $(p<0.05)$.

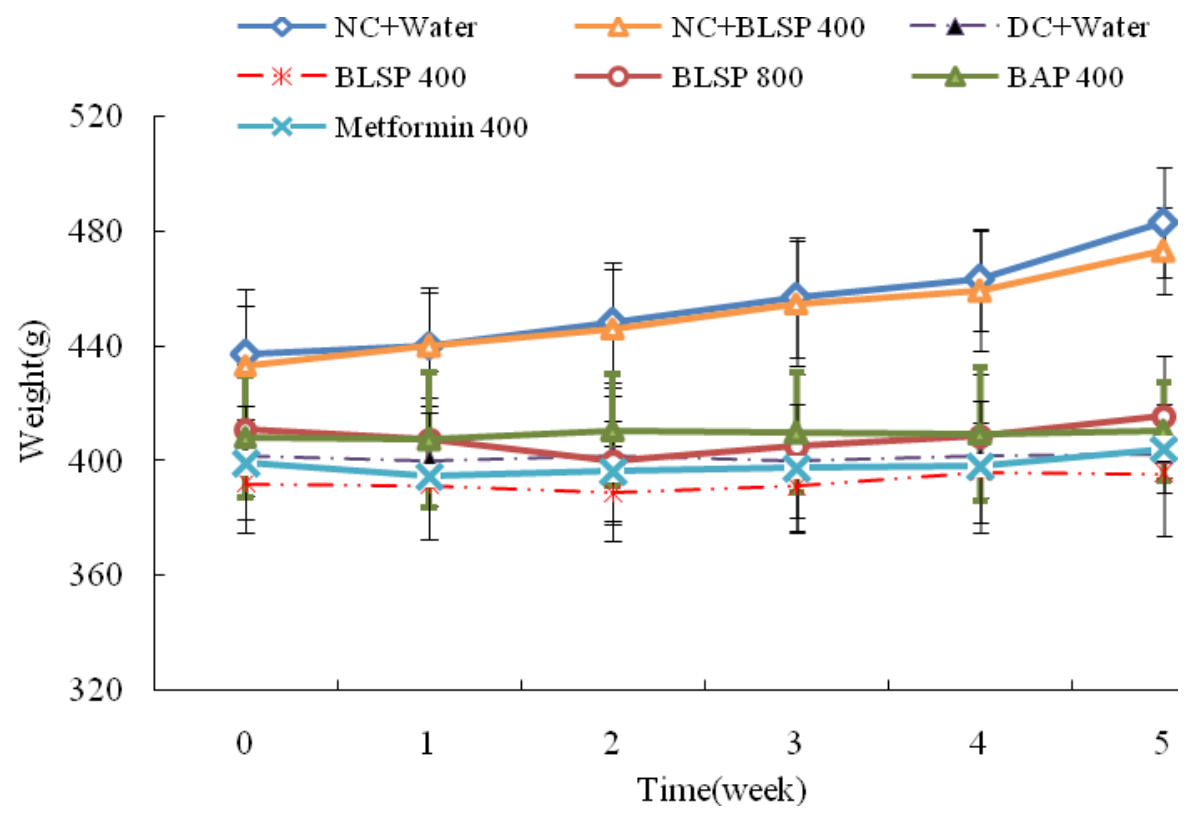


Table 3. Effect of BLSP and BAP on body weight gain, food intake, water intake in diabetic rats.

\begin{tabular}{ccccc}
\hline Group & BW gain (g) & Food intake (g/d) & Food efficiency ratio (\%) * & Water intake (mL/d) \\
\hline NC + Water & $45.82 \pm 6.35^{\mathrm{a}}$ & $23.74 \pm 1.98^{\mathrm{c}}$ & $5.49 \pm 0.11^{\mathrm{a}}$ & $45.89 \pm 5.55^{\mathrm{b}}$ \\
NC + BLSP 400 & $39.81 \pm 4.87^{\mathrm{a}}$ & $23.31 \pm 0.34^{\mathrm{c}}$ & $5.28 \pm 0.05^{\mathrm{b}}$ & $38.11 \pm 2.58^{\mathrm{b}}$ \\
DC + Water & $0.82 \pm 0.40^{\mathrm{c}}$ & $48.20 \pm 1.46^{\mathrm{a}}$ & $0.05 \pm 0.01^{\mathrm{e}}$ & $174.75 \pm 23.52^{\mathrm{a}}$ \\
BLSP 400 & $3.60 \pm 0.80^{\mathrm{b}}$ & $42.43 \pm 2.58^{\mathrm{ab}}$ & $0.24 \pm 0.01^{\mathrm{d}}$ & $161.05 \pm 34.87^{\mathrm{a}}$ \\
BLSP 800 & $4.80 \pm 0.64^{\mathrm{b}}$ & $40.86 \pm 4.11^{\mathrm{b}}$ & $0.34 \pm 0.01^{\mathrm{cd}}$ & $155.10 \pm 39.56^{\mathrm{a}}$ \\
BAP 400 & $2.07 \pm 0.66^{\mathrm{c}}$ & $45.16 \pm 4.58^{\mathrm{ab}}$ & $0.14 \pm 0.01^{\mathrm{e}}$ & $169.42 \pm 33.33^{\mathrm{a}}$ \\
Metformin 400 & $5.05 \pm 0.71^{\mathrm{b}}$ & $40.96 \pm 3.23^{\mathrm{b}}$ & $0.35 \pm 0.01^{\mathrm{c}}$ & $161.91 \pm 27.14^{\mathrm{a}}$ \\
\hline
\end{tabular}

Values are expressed as means $\pm \mathrm{SD}(n=6)$. Statistical analysis was performed using ANOVA. The means with different superscript were considered significantly different $(p<0.05)$. * Food efficiency ratio was calculated as body weight gain/food intake $\times 100 \%$.

\subsection{Effect of Processing Methods of Bitter Melon on Fasting Blood Glucose Levels (FBG) and} Insulin Levels

Table 4 presented the effect of BLSP and BAP on fasting blood glucose (FBG) levels in various experimental groups. At the beginning of the study, the FBG levels of all diabetic groups were approximately $20 \mathrm{mmol} / \mathrm{L}$, which were fourfold over the NC group. At the end of fifth week, the FBG levels of normal rats treated with distilled water kept a stable level of $5.00 \mathrm{mmol} / \mathrm{L}$ while those of normal rats treated with $400 \mathrm{mg} / \mathrm{kg} /$ day of BLSP were reduced to $4.40 \mathrm{mmol} / \mathrm{L}(p>0.05)$. All of BLSP-, BAP- and metformin-treated diabetic groups had a reduction of the FBG levels when compared with DC group. The treatment with $800 \mathrm{mg} / \mathrm{kg} /$ day of BLSP or $400 \mathrm{mg} / \mathrm{kg} /$ day of metformin could significantly decrease the FBG levels $(p<0.05)$. Of the four diabetic-treatment groups, the $800 \mathrm{mg} / \mathrm{kg} /$ day of BLSP was found to be the most effective in reducing FBG levels.

Table 4 also gave the changes of insulin levels between experimental groups treated with or without BLSP, BAP and metformin. High-fat diet feeding combined with STZ injection caused abnormal insulin secretion which finally increased the serum insulin levels of the diabetic groups significantly compared with NC group $(p<0.05)$. The administration of BLSP and metformin with the dosage of $400 \mathrm{mg} / \mathrm{kg} / \mathrm{day}$ significantly reduced the serum insulin levels compared with DC group $(p<0.05)$. However, BAP at the dosage of $400 \mathrm{mg} / \mathrm{kg} /$ day had no similar activity for balancing the serum insulin levels.

Table 4. Effect of BLSP and BAP on fasting blood glucose (FBG) changes and insulin levels in diabetic rats.

\begin{tabular}{cccc}
\hline Group & FBG Week 0 (mmol/L) & FBG Week 5 (mmol/L) & Insulin Week 5 (mIU/L) \\
\hline NC + Water & $4.90 \pm 0.38^{\mathrm{b}}$ & $5.00 \pm 0.60^{\mathrm{d}}$ & $32.49 \pm 1.48^{\mathrm{cd}}$ \\
NC + BLSP 400 & $4.68 \pm 0.54^{\mathrm{b}}$ & $4.40 \pm 0.26^{\mathrm{d}}$ & $33.47 \pm 1.35^{\mathrm{cd}}$ \\
DC + Water & $22.00 \pm 2.91^{\mathrm{a}}$ & $23.98 \pm 1.85^{\mathrm{a}}$ & $40.93 \pm 1.31^{\mathrm{a}}$ \\
BLSP 400 & $19.25 \pm 3.01^{\mathrm{a}}$ & $14.85 \pm 0.82^{\mathrm{bc}}$ & $30.74 \pm 0.38^{\mathrm{d}}$ \\
BLSP 800 & $21.40 \pm 2.31^{\mathrm{a}}$ & $12.54 \pm 2.55^{\mathrm{c}}\left(^{* *}\right)$ & $35.45 \pm 2.56^{\mathrm{bc}}$ \\
BAP 400 & $18.65 \pm 3.08^{\mathrm{a}}$ & $17.17 \pm 1.40^{\mathrm{b}}$ & $37.88 \pm 2.24^{\mathrm{ab}}$ \\
Metformin 400 & $18.62 \pm 3.49^{\mathrm{a}}$ & $12.12 \pm 1.96^{\mathrm{c}}\left(^{*}\right)$ & $33.78 \pm 0.99^{\mathrm{bcd}}$ \\
\hline
\end{tabular}

Values are expressed as means $\pm \mathrm{SD}(n=6)$. Statistical analysis was performed using ANOVA. The means with different superscript were considered significantly different $(p<0.05) .{ }^{*}$ significantly different from week $0(p<0.05){ }^{* *}$ significantly different from week $0(p<0.01)$. 
High-fat diet and STZ resulted in increases in blood glucose levels and insulin levels in the DC group. After the rats were administered BLSP, BAP and metformin for five weeks, the FBG levels of the BLSP and metformin groups improved significantly, while the BAP group decreased slightly. The increased levels of serum insulin in diabetic rats were significantly lowered by the administration of BLSP and metformin, especially the low dose group of BLSP, which were in agreement with the results obtained by Jayasooriya et al. with a marked reduction of serum glucose concentration in the freeze-dried bitter melon powder-treated group [12]. The reduction of glucose levels and serum insulin levels suggest that BLSP might have a better effect in increasing the renewal of beta cells in the pancreas, allowing for the recovery of partially destroyed beta cells [25], or displaying insulin-like properties than BAP. Metformin improves hyperglycemia primarily by suppressing glucose production by the liver, or increases insulin sensitivity, enhances peripheral glucose uptake (for example, by phosphorylating GLUT-4 enhancer factor), increases fatty acid oxidation, and decreases absorption of glucose from the gastrointestinal tract $[45,46]$. The antihyperglycemic differences between BLSP and BAP may be due to the different content of bioactive compounds, such as polypeptides, polyphenolics, terpenoids, which are consistent with the conclusions from Kunyanga et al. that high phenolic content in the foodstuffs resulted in relatively higher antioxidant and antidiabetic activities [47], and those from Keller et al. that saponins isolated from M. charantia can stimulate insulin secretion in vitro [48].

\subsection{Effect of Processing Methods of Bitter Melon on Serum Lipids in Diabetic Rats}

Diabetic rats had a significant higher serum TG level when compared to normal rats $(p<0.05)$. After being fed with $400 \mathrm{mg} / \mathrm{kg} /$ day of BLSP, the TG concentrations in diabetic rats were reduced to a significant lower level $(0.67 \mathrm{mmol} / \mathrm{L})$ than those in the DC group rats $(1.03 \mathrm{mmol} / \mathrm{L})(p<0.05)$ (Table 5). Moreover, CHOL and LDL levels increased with a decrease in the HDL levels in the diabetic groups, although no statistical differences were observed $(p>0.05)$. From the results, it is clear that the administration of BLSP had a better effect on regulating serum lipid than BAP and metformin.

Table 5. Effect of BLSP and BAP on serum lipid profiles in diabetic rats (week 5).

\begin{tabular}{ccccc}
\hline Group & TG $(\mathbf{m m o l} / \mathbf{L})$ & CHOL $(\mathbf{m m o l} / \mathbf{L})$ & HDL $(\mathbf{m m o l} / \mathbf{L})$ & LDL $(\mathbf{m m o l} / \mathbf{L})$ \\
\hline NC + Water & $0.53 \pm 0.17^{\mathrm{b}}$ & $1.44 \pm 0.19^{\mathrm{a}}$ & $1.35 \pm 0.23^{\mathrm{a}}$ & $0.38 \pm 0.04^{\mathrm{a}}$ \\
$\mathrm{NC}+$ BLSP 400 & $0.50 \pm 0.07^{\mathrm{b}}$ & $1.35 \pm 0.22^{\mathrm{a}}$ & $1.26 \pm 0.20^{\mathrm{a}}$ & $0.36 \pm 0.09^{\mathrm{a}}$ \\
DC + Water & $1.03 \pm 0.27^{\mathrm{a}}$ & $1.62 \pm 0.11^{\mathrm{a}}$ & $1.07 \pm 0.08^{\mathrm{a}}$ & $0.42 \pm 0.05^{\mathrm{a}}$ \\
BLSP 400 & $0.67 \pm 0.07^{\mathrm{b}}$ & $1.52 \pm 0.31^{\mathrm{a}}$ & $1.18 \pm 0.33^{\mathrm{a}}$ & $0.39 \pm 0.12^{\mathrm{a}}$ \\
BLSP 800 & $0.74 \pm 0.14^{\mathrm{ab}}$ & $1.53 \pm 0.34^{\mathrm{a}}$ & $1.28 \pm 0.08^{\mathrm{a}}$ & $0.38 \pm 0.08^{\mathrm{a}}$ \\
BAP 400 & $0.85 \pm 0.02^{\mathrm{ab}}$ & $1.60 \pm 0.27^{\mathrm{a}}$ & $1.14 \pm 0.19^{\mathrm{a}}$ & $0.39 \pm 0.08^{\mathrm{a}}$ \\
Metformin 400 & $0.88 \pm 0.30^{\mathrm{ab}}$ & $1.56 \pm 0.36^{\mathrm{a}}$ & $1.13 \pm 0.24^{\mathrm{a}}$ & $0.41 \pm 0.10^{\mathrm{a}}$ \\
\hline
\end{tabular}

Values are expressed as means $\pm \mathrm{SD}(n=6)$. Statistical analysis was performed using ANOVA. The means with different superscript were considered significantly different $(p<0.05)$.

Type 2 diabetes mellitus is associated with profound alterations in the plasma lipid and lipoprotein profile. The levels of TG, LDL and CHOL increase while the HDL levels decline [49]. Bitter melon reduces serum TG level. Furthermore, the obtained data proved that BLSP with $400 \mathrm{mg} / \mathrm{kg} / \mathrm{day}$ could reduce the serum TG level significantly, which is consistent with those obtained by Senanayake et al., 
by using methanol to extract the active components from bitter melon [24]. However, serum cholesterol levels in various experimental groups had a slight difference from those of Ahmed et al. [13]. The changes in bioactive components concentrations released from bitter melons might make the contribution. In the present study, BLSP can better ameliorate serum TG level of rats than BAP, which also proved that powder size and lyophilization can improve the release of active components, as well as retaining their bioactivity [50]. The main components to make this contribution may be saponins. Popovich et al. found that bitter melon triterpenoid extract reduces lipid accumulation and adiponectin expression in 3T3-L1 cells [51].

\subsection{Effect of Processing Methods of Bitter Melon on MDA Levels and the SOD and GPX Activities in} Diabetic Rats

The MDA levels and the activities of enzymatic antioxidants (SOD and GPx) in the livers were determined (Table 6). The treatment of BLSP, BAP and metformin had no obvious effect on reducing MDA levels and improving the activities of GPx of the diabetic groups. However, the activities of SOD in the BLSP 800 group and Metformin 400 group significantly increased as compared to the DC group ( $p<0.05$ ), which was close to the levels of the NC group.

Table 6. Effect of BLSP and BAP on liver MDA levels, the activities of SOD and GPx in diabetic rats (week 5).

\begin{tabular}{cccc}
\hline Group & MDA (nmol/mgprot) & SOD (U/mgprot) & GPx $(\boldsymbol{\mu m o l} / \mathbf{m i n} / \mathbf{L})$ \\
\hline NC + Water & $27.71 \pm 1.50^{\mathrm{a}}$ & $407.57 \pm 55.15^{\mathrm{ab}}$ & $269.83 \pm 37.76^{\mathrm{a}}$ \\
NC + BLSP 400 & $27.44 \pm 1.65^{\mathrm{a}}$ & $453.63 \pm 57.65^{\mathrm{a}}$ & $227.66 \pm 14.37^{\mathrm{a}}$ \\
DC + Water & $31.19 \pm 3.97^{\mathrm{a}}$ & $291.73 \pm 39.16^{\mathrm{c}}$ & $262.47 \pm 36.93^{\mathrm{a}}$ \\
BLSP 400 & $29.47 \pm 1.94^{\mathrm{a}}$ & $341.22 \pm 58.21^{\mathrm{bc}}$ & $245.25 \pm 35.41^{\mathrm{a}}$ \\
BLSP 800 & $30.71 \pm 5.24^{\mathrm{a}}$ & $397.04 \pm 23.48^{\mathrm{ab}}$ & $236.01 \pm 65.47^{\mathrm{a}}$ \\
BAP 400 & $31.67 \pm 7.01^{\mathrm{a}}$ & $304.51 \pm 65.65^{\mathrm{c}}$ & $278.42 \pm 48.75^{\mathrm{a}}$ \\
Metformin 400 & $30.55 \pm 2.95^{\mathrm{a}}$ & $416.76 \pm 45.47^{\mathrm{ab}}$ & $253.30 \pm 22.25^{\mathrm{a}}$ \\
\hline
\end{tabular}

Values are expressed as means $\pm \mathrm{SD}(n=6)$. Statistical analysis was performed using ANOVA. The means with different superscript were considered significantly different $(p<0.05)$.

\subsection{Histologic Findings}

Figure 3 presented the histologic findings of the pancreas in the diabetic rats. From Figure 3, the pancreas was partially damaged by STZ, including atrophy and multiple irregular projections of islets. When diabetic animals were treated with BLSP and BAP for five weeks, the islets were partially renovated, especially in the BLSP 400 group. There is no difference of the relative islet cell mass in the rat pancreas among the BLSP, BAP and metformin groups $(p>0.05)$, while the increase of islet cell mass is significant compared with the untreated diabetic rats (Figure 4). 
Figure 3. Histopathological analysis of Langerhans islets of diabetic rat pancreas (original magnification $400 \times$ ). The pancreatic sections were stained with hematoxylin and eosin stain (H and $\mathrm{E})$.

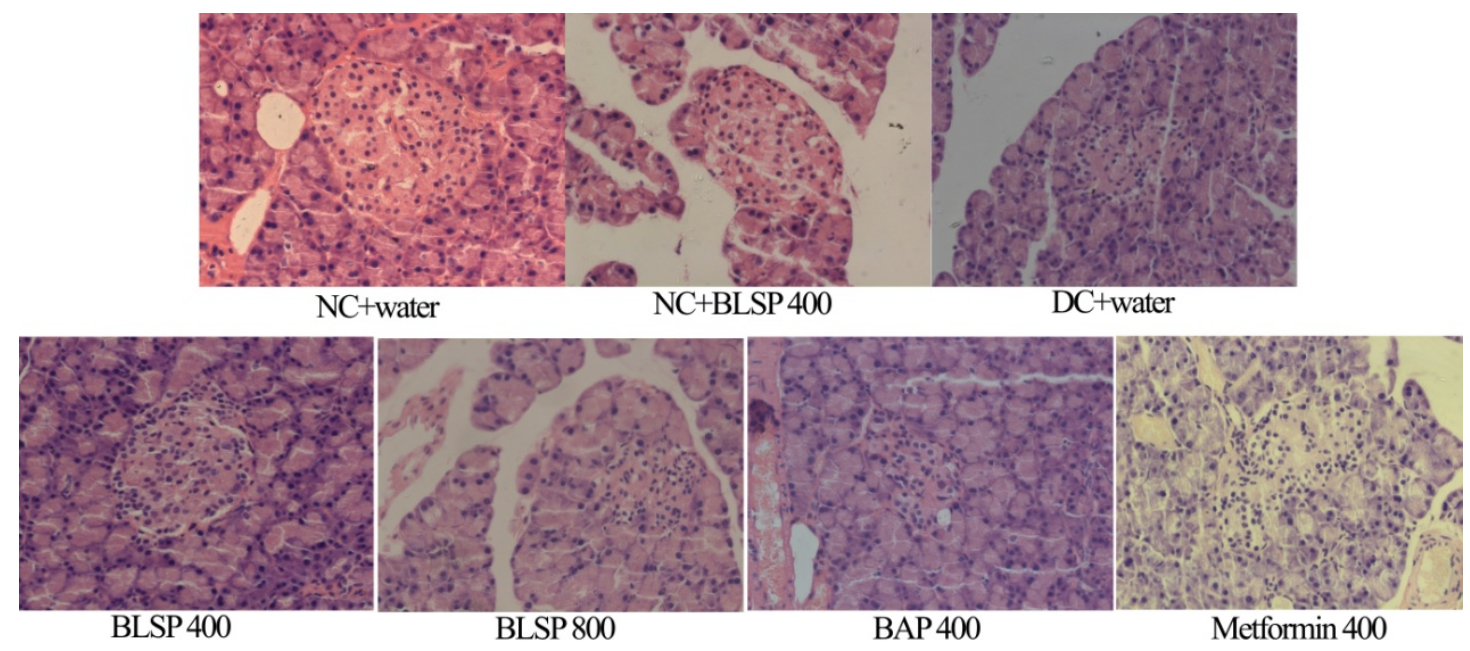

Figure 4. Effect of BLSP and BAP on islet cell mass in diabetic rats. Values are expressed as means $\pm \mathrm{SD}(n=6)$. Statistical analysis was performed using ANOVA. The means with different superscript were considered significantly different $(p<0.05)$.

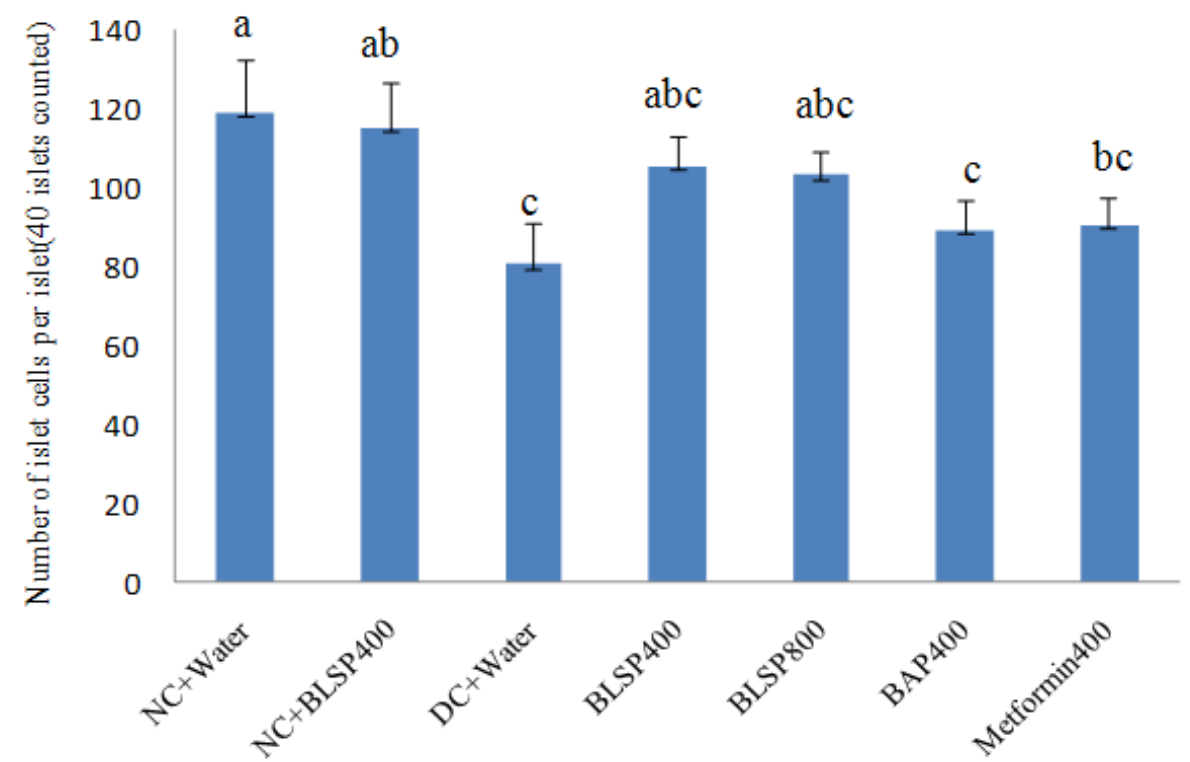

The interesting observation in this research was the pathophysiologic changes of islets in diabetic rats treated with or without bitter melon samples. Diabetic rats had the islets with a relatively decreased population of insulin-producing beta cells and multiple irregular projections [52]. In the BLSP 400 group, pancreatic islets showed predominantly insulin-producing beta cells with basophilic cytoplasm and a few eosinophilic glucagon-producing alpha cells, and also the arrangement of the endocrine cells in the islets appeared similar to normal. Ahmed et al. also found that bitter melon fruit juice may have a role in the renewal of beta cells in STZ-diabetic rats [25]. However, BAP 400 group and Metformin 400 group did not show any significant effect on renovating islets of the diabetic rats. 
Pinent et al. have correlated flavonoid intake to increases in beta cell mass, with the flavonoids either inhibiting apoptosis or promoting proliferation of beta cells [53]. Bitter melon is a rich source of flavonoids, and this may contribute to the BLSP capacity to renovate the islets of rats. Furthermore, the difference between BLSP and BAP can be due to the difference in the changes of nutritious components (such as flavonoids) released based on the different particle sizes.

It was evident in the study that high-fat diet and STZ-induced rats had hyperlipidaemia and hypertriglyceridemia [38,54], while BLSP-treated rats had reduced glucose concentrations and improved insulin sensitivity. The main mechanism may be that bitter melon can regulate PPAR $\alpha$-mediated pathway or influence PPAR $\gamma$-mediated pathway [40]. In addition, the main nutrition components associated with the effects may be pholenols, flavonoids and saponins. We speculate that BLSP could be another choice in the protection against visceral obesity and type 2 diabetes.

\section{Experimental Section}

\subsection{Plant Material}

The fresh fruits of wild bitter melon were obtained from Lvjian Agricultural Station (Yangzhong City, China) and were authenticated by Jiangsu Academy of Agricultural Science. The bitter melon selected for the present study had a 20-25 mm diameter and green appearance.

Bitter melon lyophilized superfine grinding powder (BLSP) was prepared by washing the unripe bitter melons with tap water, removing the seeds, lyophilizing the remaining portion with the pressure of $30 \mathrm{~Pa}$ for $24 \mathrm{~h}$ at $5{ }^{\circ} \mathrm{C}$, and superfinely ground with a HSF high-speed hammer mill (National Special Superfine Powder Engineering Research Center of China, Nanjing, China). The preparation methods of bitter melon hot air drying superfine grinding powder (BAP) was similar to those of the BLSP, except the $60^{\circ} \mathrm{C}$ hot air procedure $(24 \mathrm{~h}$ ) and grounding with a QE-100g mill (Zhejiang Yili Co., Jinghua, China). BAP and BLSP were filtered through a $150 \mu \mathrm{m}$ screen before further experiments. The obtained samples were stored at $4{ }^{\circ} \mathrm{C}$ for further use.

\subsection{Determination of Physical Properties of BLSP and BAP}

The Morphological characterization of BLSP and BAP was analyzed with a Field Emission Scanning Electron Microscope (FE-SEM: Jeol JSM-7001F: with Au-coated, operated at $10 \mathrm{~kW}$ ). Particle size distribution of BLSP and BAP were measured by a laser diffraction instrument (Mastersizer 2000, UK). The moisture contents were determined by using a HB43-S moisture analyzer (Mettler Toledo, Switzerland). The water activity (Aw) values were determined by using AQUA Lab (Decagon Devices, Inc., USA). The water solubility index of 20 min was determined by using the method described by Zhao et al. [55].

\subsection{Analysis of Chemical Components of BLSP and BAP}

Two grams of powders were extracted with $100 \mathrm{~mL}$ distilled water at $100{ }^{\circ} \mathrm{C}$ for $30 \mathrm{~min}$, filtering the infusions to obtain the resulting supernatant. After cooling and filtering, the volume was made up to $100 \mathrm{~mL}$ with distilled water. Water-soluble nitrogen content was analyzed with the Bradford procedure based on an established calibration curve. The results were expressed as BSA (Bovine 
serum albumin) equivalents in $\mathrm{mg} / \mathrm{g}$ dry material. Additionally, water-soluble sugar content was analyzed by using the anthranone reagent and the results were expressed as D-glucose equivalents percent. The total of polyphenols was analyzed by the Folin-Ciocalteu method. Briefly, this solution $(0.5 \mathrm{~mL})$ was mixed with $2.5 \mathrm{~mL}$ of distilled water, $1.5 \mathrm{~mL}$ of $7.5 \%$ sodium carbonate $\left(\mathrm{Na}_{2} \mathrm{CO}_{3}\right)$, and $0.5 \mathrm{~mL}$ of Folin-Ciocalteau reagent. After incubation at $45{ }^{\circ} \mathrm{C}$ for $30 \mathrm{~min}$, the absorbance of the reaction mixture absorbance was measured at $750 \mathrm{~nm}$, and the content was expressed as gallic acid equivalents in $\mathrm{mg} / \mathrm{g}$ dry material.

The total flavonoid content was determined according to the aluminum chloride colorimetric method [6]. The total flavonoid content was expressed in milligrams of rutin equivalents per gram of dry material. The total saponin content was determined used the method described by Xu \& Dong [56] and expressed as Ginsenoside Rg1 equivalents percent.

\subsection{Animals}

Sprague-Dawley male rats weighing $200 \pm 20 \mathrm{~g}$ were obtained from the Laboratory Animal Research Center of Jiangsu University (LARC, Zhenjiang, China) with the license number SCXK (SU) 2009-0002 and SYXK (SU) 2008-0024. The rats were caged individually in LARC at temperature of $22 \pm 2{ }^{\circ} \mathrm{C}$ and a relative humidity of $40 \%-60 \%$, and artificially illuminated on an approximate $12 \mathrm{hr}-$ light/dark cycle. The air exchange was about 18 times/h. All the rats were provided food and filtered tap water ad libitum.

\subsection{Induction of Diabetes}

Rats were randomly separated into two groups: normal control (NC) and diabetic groups. The NC group was fed with a basic diet and experimental animals were fed with a high-fat and high-sucrose diet (containing of $7 \%$ lard, 15\% sucrose and 78\% basic diet) for 4 weeks. After feeding the rats with these diets for 4 weeks, the rats were then made to fast overnight before treatment. Type 2 diabetic rats were induced by a single intraperitoneal injection of STZ (Sigma Chemical Co., St. Louis, MO, USA) freshly dissolved in a $0.1 \mathrm{~mol} / \mathrm{L}$ citrate buffer $(\mathrm{pH} 4.5)$ at a dosage of $35 \mathrm{mg} / \mathrm{kg}$ body weight. The NC group was administered with citrate buffer $(\mathrm{pH} 4.5)$. Three days later, the rats were confirmed as the diabetic model when their fasting plasma glucose levels exceeded $11.1 \mathrm{mmol} / \mathrm{L}$. Diabetes were stabilized in these STZ-treated rats over a period of 7 days before the experiment.

\subsection{Experimental Design}

Experimental rats with 12 of normal model and 30 of STZ-diabetic model were divided into 7 groups of 6 each. Group $1(\mathrm{NC}+$ water $)$ consisted of normal rats treated with distilled water $(4 \mathrm{~mL} / \mathrm{kg}$ body weight); Group 2 (NC + BLSP 400) consisted of normal rats treated with BLSP (400 mg/kg bw); Group 3 (DC (diabetic control) + water) consisted of diabetic rats treated with distilled water $(4 \mathrm{~mL} / \mathrm{kg}$ bw); Group 4 (BLSP 400) consisted of diabetic rats treated with BLSP (400 mg/kg bw); Group 5 (BLSP 800) consisted of diabetic rats treated with BLSP (800 mg/kg bw); Group 6 (BAP 400) consisted of diabetic rats treated with BAP (400 mg/kg bw); Group 7 (Metformin 400) consisted of 
diabetic rats treated with $400 \mathrm{mg} / \mathrm{kg}$ bw of metformin (Beijing Jingfeng Pharmaceutical CO., LTD, Beijing, China).

During the five-week treatment, the body weight of each rat and the food/water intake volumes were measured weekly, then the animals were anesthetized with chloral hydrate. Blood samples were collected via abdominal aorta puncture. The blood samples were centrifuged at $3500 \mathrm{rpm}$ for $10 \mathrm{~min}$ to obtain the serum, which was kept at $-20^{\circ} \mathrm{C}$ for further analysis.

\subsection{Blood Biochemical Assays}

Fasting blood glucose was measured using OneTouch Ultra Blood Glucose Meter (Johnson \& Johnson Medical (China) Ltd., Shanghai, China).

The sera were assayed for triglycerides (TG), cholesterol (CHOL), high-density lipoproteins cholesterol (HDLC) and low-density lipoproteins cholesterol (LDLC) levels with an Olympus AU2700 Clinical Chemistry Analyzer (Olympus Inc., Japan). The insulin levels were determined using commercial rat insulin ELISA kits (R \& D Systems China Co. Ltd., Shanghai, China).

\subsection{Oxidative Stress Markers and Antioxidant Enzymes}

The end product of liver tissue lipid peroxidation quantity was expressed by the content of the malondialdehyde (MDA). The MDA content was determined using commercially available kits (Nanjing Jiancheng Bio CO., Nanjing, China). While the levels of SOD and glutathione peroxidase (GPx) of the liver tissue were also determined using commercially available kits (Nanjing Jiancheng Bio CO., Nanjing, China).

\subsection{Histopathologic Procedures}

Pancreatic tissues were harvested from the sacrificed rats. The tissues were fixed in $10 \%$ neutral buffered formalin, embedded in paraffin, cut to approximately $4 \mu \mathrm{m}$ sections, and stained with hematoxylin and eosin (H\&E). The slides were viewed on a Zeiss Axiovert 40 Microscope (Carl Zeiss, Oberkochen, Germany).

\subsection{Statistical Analyses}

The data were presented as group mean values \pm SD (standard deviation) and were analyzed by one-way analysis of variance (ANOVA). All the statistical analyses were performed using SPSS v14.0 (SPSS Inc., Chicago, IL, USA). $p$ values $<0.05$ were considered as significant.

\section{Conclusions}

Superfine grinding and lyophilization are helpful for improving extraction of proteins, polysaccharides and other bioactive components such as total pholenols, flavonoids and saponins from bitter melon, which might attribute to the more significant blood glucose- and TG- lowering effect and the renovated islets of rats with high-fat diet and STZ- induced diabetes than those of BAP. These findings also provided a direct utilization method of bitter melon as a suitable functional food to relieve symptoms of diabetes. Further investigations will be focused on investigating the relationship 
of the antihyperglycemic molecular mechanism of BLSP with particle size and proposing an energy-saving grinding process.

\section{Acknowledgments}

This research was partially funded by the National Natural Science Foundation of China (3104006) and Graduate Research and Innovation Projects of Jiangsu Province (XZZ11-0586).

\section{References}

1. Li, M.; Chen, Y.; Liu, Z.; Shen, F.; Bian, X.; Meng, Y. Anti-tumor activity and immunological modification of ribosome-inactivating protein (RIP) from Momordica charantia by covalent attachment of polyethylene glycol. Acta Biochim. Biophys. Sin. 2009, 41, 792-799.

2. Fang, E.F.; Ng, T.B. Bitter gourd (Momordica charantia) is a cornucopia of health: A review of its credited antidiabetic, anti-HIV, and antitumor properties. Curr. Mol. Med. 2011, 11, 417-436.

3. Nerurkar, P.; Ray, R.B. Bitter melon: Antagonist to cancer. Pharm. Res. 2010, 27, 1049-1053.

4. Lii, C.K.; Chen, H.W.; Yun, W.T.; Liu, K.L. Suppressive effects of wild bitter gourd (Momordica charantia Linn. var. abbreviata ser.) fruit extracts on inflammatory responses in RAW 264.7 macrophages. J. Ethnopharmacol. 2009, 122, 227-233.

5. Kubola, J.; Siriamornpun, S. Phenolic contents and antioxidant activities of bitter gourd (Momordica charantia L.) leaf, stem and fruit fraction extracts in vitro. Food Chem. 2008, 110, 881-890.

6. Wu, S.J.; Ng, L.T. Antioxidant and free radical scavenging activities of wild bitter melon (Momordica charantia Linn. var. abbreviata Ser.) in Taiwan. LWT-Food Sci. Technol. 2008, 41, 323-330.

7. Braca, A.; Siciliano, T.; D’Arrigo, M.; Germanò, M.P. Chemical composition and antimicrobial activity of Momordica charantia seed essential oil. Fitoterapia 2008, 79, 123-125.

8. Mwambete, K. The in vitro antimicrobial activity of fruit and leaf crude extracts of Momordica charantia: A Tanzania medicinal plant. Afr. Health Sci. 2009, 9, 34-39.

9. Miura, T.; Itoh, C.; Iwamoto, N.; Kato, M.; Kawai, M.; Park, S.R.; Suzuki, I. Hypoglycemic activity of the fruit of the Momordica charantia in type 2 diabetic mice. J. Nutr. Sci. Vitaminol. 2001, 47, 340-344.

10. Reyes, B.A.S.; Bautista, N.D.; Tanquilut, N.C.; Anunciado, R.V.; Leung, A.B.; Sanchez, G.C.; Magtoto, R.L.; Castronuevo, P.; Tsukamura, H.; Maeda, K.I. Anti-diabetic potentials of Momordica charantia and Andrographis paniculata and their effects on estrous cyclicity of alloxan-induced diabetic rats. J. Ethnopharmacol. 2006, 105, 196-200.

11. Krawinkel, M.B.; Keding, G.B. Bitter gourd (Momordica charantia): A dietary approach to hyperglycemia. Nutr. Rev. 2006, 64, 331-337.

12. Jayasooriya, A.P.; Sakono, M.; Yukizaki, C.; Kawano, M.; Yamamoto, K.; Fukuda, N. Effects of Momordica charantia powder on serum glucose levels and various lipid parameters in rats fed with cholesterol-free and cholesterol-enriched diets. J. Ethnopharmacol. 2000, 72, 331-336. 
13. Ahmed, I.; Lakhani, M.S.; Gillett, M.; John, A.; Raza, H. Hypotriglyceridemic and hypocholesterolemic effects of anti-diabetic Momordicacharantia (karela) fruit extract in streptozotocin-induced diabetic rats. Diabetes Res. Clin. Pract. 2001, 51, 155-161.

14. Grover, J.; Yadav, S. Pharmacological actions and potential uses of Momordica charantia: A review. J. Ethnopharmacol. 2004, 93, 123-132.

15. Karunanayake, E.H.; Tennekoon, K.H. Search of novel hypoglycemic agents from medicinal plants. In Diabetes Mellitus and Its Complications, An Update; Sharma, A.K., Ed.; Macmillan India Ltd.: New Delhi, India, 1993; pp. 192-205.

16. Islam, S.; Jalaluddin, M.; Hettiarachchy, N.S. Bio-active compounds of bitter melon genotypes (Momordica charantia L.) in relation to their physiological functions. Funct. Foods Health Dis. 2011, 2, 61-74.

17. Akhtar, M.S.; Athar, M.A.; Yaqub, M. Effect of Momordica charantia on blood glucose level of normal and alloxan-diabetic rabbits. Planta Med. 1981, 42, 205-212.

18. Kar, A.; Choudhary, B.; Bandyopadhyay, N. Comparative evaluation of hypoglycaemic activity of some Indian medicinal plants in alloxan diabetic rats. J. Ethnopharmacol. 2003, 84, 105-108.

19. Fuangchan, A.; Sonthisombat, P.; Seubnukarn, T.; Chanouan, R.; Chotchaisuwat, P.; Sirigulsatien, V.; Ingkaninan, K.; Plianbangchang, P.; Haines, S.T. Hypoglycemic effect of bitter melon compared with metformin in newly diagnosed type 2 diabetes patients. J. Ethnopharmacol. 2011, 134, 422-428.

20. Shih, C.-C.; Lin, C.-H.; Lin, W.-L.; Wu, J.-B. Momordica charantia extract on insulin resistance and the skeletal muscle GLUT4 protein in fructose-fed rats. J. Ethnopharmacol. 2009, 123, 82-90.

21. Raman, A.; Lau, C. Anti-diabetic properties and phytochemistry of Momordica charantia L. (Cucurbitaceae). Phytomedicine 1996, 2, 349-362.

22. Yibchok, S.; Adisakwattana, S.; Cheng, Y.Y.; Sangvanich, P.; Roengsumran, S.; Hsu, W.H. Slow acting protein extract from fruit pulp of Momordica charantia with insulin secretagogue and insulinomimetic activities. Biol. Pharm. Bull. 2006, 29, 1126-1131.

23. Chen, Q.; Chan, L.L.Y.; Li, E.T.S. Bitter melon (Momordica charantia) reduces adiposity, lowers serum insulin and normalizes glucose tolerance in rats fed a high fat diet. J. Nutr. 2003, 133, 1088-1093.

24. Senanayake, G.V.K.; Maruyama, M.; Shibuya, K.; Sakono, M.; Fukuda, N.; Morishita, T.; Yukizaki, C.; Kawano, M.; Ohta, H. The effects of bitter melon (Momordica charantia) on serum and liver triglyceride levels in rats. J. Ethnopharmacol. 2004, 91, 257-262.

25. Ahmed, I.; Adeghate, E.; Sharma, A.K.; Pallot, D.J.; Singh, J. Effects of Momordica charantia fruit juice on islet morphology in the pancreas of the streptozotocin-diabetic rat. Diabetes Res. Clin. Pract. 1998, 40, 145-151.

26. Kumar, R.; Balaji, S.; Uma, T.S.; Sehgal, P.K. Fruit extracts of Momordica charantia potentiate glucose uptake and up-regulate Glut-4, PPAR $\gamma$ and PI3K. J. Ethnopharmacol. 2009, 126, 533-537.

27. Nerurkar, P.V.; Lee, Y.K.; Motosue, M.; Adeli, K.; Nerurkar, V.R. Momordica charantia (bitter melon) reduces plasma apolipoprotein B-100 and increases hepatic insulin receptor substrate and phosphoinositide-3 kinase interactions. Br. J. Nutr. 2008, 100, 751-759. 
28. Sridhar, M.; Vinayagamoorthi, R.; Arul Suyambunathan, V.; Bobby, Z.; Selvaraj, N. Bitter gourd (Momordica charantia) improves insulin sensitivity by increasing skeletal muscle insulin-stimulated IRS-1 tyrosine phosphorylation in high-fat-fed rats. Br. J. Nutr. 2008, 99, 806-812.

29. Tkacova, K.; Stevulova, N. Selected problems of the dispersity analysis of milled ultrafine powders. Freiberger Forsch. A (Partik.) 1998, A841, 14-25.

30. Wu, G.; Zhang, M.; Wang, Y.; Mothibe, K.J.; Chen, W. Production of silver carp bone powder using superfine grinding technology: Suitable production parameters and its properties. J. Food Eng. 2012, 109, 730-735.

31. Zhao, X.; Du, F.; Zhu, Q.; Qiu, D.; Yin, W.; Ao, Q. Effect of superfine pulverization on properties of Astragalus membranaceus powder. Powder Technol. 2010, 203, 620-625.

32. Zhao, X.-Y.; Ao, Q.; Yang, L.-W.; Yang, Y.-F.; Sun, J.-C.; Gai, G.-S. Application of superfine pulverization technology in Biomaterial Industry. J. Taiwan Inst. Chem. Eng. 2009, 40, 337-343.

33. Maaroufi, C.; Melcion, J.; de Monredon, F.; Giboulot, B.; Guibert, D.; Le Guen, M.P. Fractionation of pea flour with pilot scale sieving. I. Physical and chemical characteristics of pea seed fractions. Anim. Feed Sci. Technol. 2000, 85, 61-78.

34. Sakata, Y.; Shiraishi, S.; Otsuka, M. Effect of pulverization of the bulk powder on the hydration of creatine anhydrate tablets and their pharmaceutical properties. Colloids Surf. B Biointerfaces 2005, 46, 92-100.

35. Zhu, K.; Huang, S.; Peng, W.; Qian, H.; Zhou, H. Effect of ultrafine grinding on hydration and antioxidant properties of wheat bran dietary fiber. Food Res. Int. 2010, 43, 943-948.

36. Hu, J.; Chen, Y.; Ni, D. Effect of superfine grinding on quality and antioxidant property of fine green tea powders. LWT-Food Sci. Technol. 2012, 45, 8-12.

37. Król, E.; Krejpcio, Z. Evaluation of anti-diabetic potential of chromium(III) propionate complex in high-fat diet fed and STZ injected rats. Food Chem. Toxicol. 2011, 49, 3217-3223.

38. Sahin, K.; Onderci, M.; Tuzcu, M.; Ustundag, B.; Cikim, G.; Ozercan, İ.H.; Sriramoju, V.; Juturu, V.; Komorowski, J.R. Effect of chromium on carbohydrate and lipid metabolism in a rat model of type 2 diabetes mellitus: The fat-fed, streptozotocin-treated rat. Metabolism 2007, 56, 1233-1240.

39. Zheng, X.-K.; Zhang, L.; Wang, W.-W.; Wu, Y.-Y.; Zhang, Q.-B.; Feng, W.-S. Anti-diabetic activity and potential mechanism of total flavonoids of Selaginella tamariscina (Beauv.) Spring in rats induced by high fat diet and low dose STZ. J. Ethnopharmacol. 2011, 137, 662-668.

40. Shih, C.-C.; Lin, C.-H.; Lin, W.-L. Effects of Momordica charantia on insulin resistance and visceral obesity in mice on high-fat diet. Diabetes Res. Clin. Pract. 2008, 81, 134-143.

41. Kang, J.S.; Lee, W.K.; Lee, C.W.; Yoon, W.K.; Kim, N.; Park, S.-K.; Lee, H.-S.; Park, H.K.; Han, S.-B.; Yun, J.; et al. Improvement of high-fat diet-induced obesity by a mixture of red grape extract, soy isoflavone and l-carnitine: Implications in cardiovascular and non-alcoholic fatty liver diseases. Food Chem. Toxicol. 2011, 49, 2453-2458.

42. Mythili, M.D.; Vyas, R.; Akila, G.; Gunasekaran, S. Effect of streptozotocin on the ultrastructure of rat pancreatic islets. Microsc. Res. Tech. 2004, 63, 274-281.

43. Srinivasan, K.; Viswanad, B.; Asrat, L.; Kaul, C.L.; Ramarao, P. Combination of high-fat diet-fed and low-dose streptozotocin-treated rat: A model for type 2 diabetes and pharmacological screening. Pharmacol. Res. 2005, 52, 313-320. 
44. Kasbia, G.S.; Arnason, J.T.; Imbeault, P. No effect of acute, single dose oral administration of Momordica charantia Linn., on glycemia, energy expenditure and appetite: A pilot study in non-diabetic overweight men. J. Ethnopharmacol. 2009, 126, 127-133.

45. Kirpichnikov, D.; McFarlane, S.I.; Sowers, J.R. Metformin: An update. Ann. Intern. Med. 2002, 137, 25-33.

46. Collier, C.A.; Bruce, C.R.; Smith, A.C.; Lopaschuk, G.; Dyck, D.J. Metformin counters the insulin-induced suppression of fatty acid oxidation and stimulation of triacylglycerol storage in rodent skeletal muscle. Am. J. Physiol. Endocrinol. Metabol. 2006, 291, E182-E189.

47. Kunyanga, C.N.; Imungi, J.K.; Okoth, M.W.; Biesalski, H.K.; Vadivel, V. Total phenolic content, antioxidant and antidiabetic properties of methanolic extract of raw and traditionally processed Kenyan indigenous food ingredients. LWT-Food Sci. Technol. 2012, 45, 269-276.

48. Keller, A.C.; Ma, J.; Kavalier, A.; He, K.; Brillantes, A.M.B.; Kennelly, E.J. Saponins from the traditional medicinal plant Momordica charantia stimulate insulin secretion in vitro. Phytomedicine 2011, 19, 32-37.

49. Palumbo, P. Metformin: Effects on CardiovascularRisk Factors in Patients with Non-Insulin-Dependent Diabetes Mellitus. J. Diabetes Complicat. 1998, 12, 110-119.

50. Zhang, M.; Zhang, C.-J.; Shrestha, S. Study on the preparation technology of superfine ground powder of Agrocybe chaxingu Huang. J. Food Eng. 2005, 67, 333-337.

51. Popovich, D.G.; Li, L.; Zhang, W. Bitter melon (Momordica charantia) triterpenoid extract reduces preadipocyte viability, lipid accumulation and adiponectin expression in 3T3-L1 cells. Food Chem. Toxicol. 2010, 48, 1619-1626.

52. Masiello, P. Animal models of type 2 diabetes with reduced pancreatic $\beta$-cell mass. Int. J. Biochem. Cell Biol. 2006, 38, 873-893.

53. Pinent, M.; Castell, A.; Baiges, I.; Montagut, G.; Arola, L.; Ardévol, A. Bioactivity of Flavonoids on Insulin-Secreting Cells. Compr. Rev. Food Sci. Food Saf. 2008, 7, 299-308.

54. Ishii, Y.; Ohta, T.; Sasase, T.; Morinaga, H.; Hata, T.; Miyajima, K.; Katusda, Y.; Masuyama, T.; Shinohara, M.; Kakutani, M.; et al. A high-fat diet inhibits the progression of diabetes mellitus in type 2 diabetic rats. Nutr. Res. 2010, 30, 483-491.

55. Zhao, X.; Yang, Z.; Gai, G.; Yang, Y. Effect of superfine grinding on properties of ginger powder. J. Food Eng. 2009, 91, 217-222.

56. Xu, B.; Dong, Y. Determination on Total Saponins of Momordica Charantia L. by Spectrophotometry. Food Sci. 2005, 10, 165-169.

(C) 2012 by the authors; licensee MDPI, Basel, Switzerland. This article is an open access article distributed under the terms and conditions of the Creative Commons Attribution license (http://creativecommons.org/licenses/by/3.0/). 